\title{
Biotecnologia E Saúde Pública: Suas Interfaces Teórico-Conceituais E Contribuições Para Pensar A Odontologia Neste Diálogo
}

\author{
Biotechnology And Public Health: Its Theoretical Interfaces And Contributions To Think Dentistry \\ In This Dialogue \\ Biotecnología Y Salud Pública: Sus Interfaces Teóricas Y Contribuciones A Pensar La Odontología \\ En Este Diálogo
}

Leonardo Carnut ${ }^{1}$, Fábio Solón Tajra²,Áurea Maria Zöllner Ianni ${ }^{3}$, Celso Zilbovicius ${ }^{4}$

Resumo: Trata-se de um ensaio que visa discutir aspectos relativos às práticas biotecnológicas em prol de melhorias destinadas aos serviços de saúde pública e às necessidades das populações. Um dos focos desta discussão orbita ao redor da Odontologia e inclui o seguinte questionamento: há espaço para esta área no diálogo entre biotecnologia e saúde pública? Diversos estudiosos indicam a necessidade da análise da aplicabilidade dos produtos biotecnológicos à realidade da Odontologia na saúde pública, bem como da garantia de relevância social e econômica relacionada com o avanço do conhecimento e aplicação dos resultados, especialmente no que tange a solução de problemas prioritários de saúde, adequando-os à Política Nacional de Ciência, Tecnologia e Inovação em Saúde (PNCTIS) e à Agenda Nacional de Prioridades de Pesquisa em Saúde (ANPPS). Neste sentido, caberia, portanto, à comunidade odontológica entender e apropriar-se do conhecimento relativo a este tema que, na atualidade, se torna mais um desafio à implantação de uma saúde bucal pública e de qualidade no maior sistema de saúde universal do mundo.

\footnotetext{
${ }^{1}$ Doutor em Saúde Pública (Política, Gestão e Saúde) (FSP-USP). Mestre em Odontologia (Saúde Coletiva) (FOP-UPE). Especialista em Direito Sanitário (IDISA-UNICAMP); Especialista em Saúde da Família (IMIP-PE); Especialista em Saúde Coletiva (UPE); Cirurgião-dentista (UPE); Cientista Social (UFPE).Atualmente é Professor Assitente da Universidade de Pernambuco, atuando nos cursos de Graduação em Odontologia, Saúde Coletiva e Ciências Sociais.

ORCID: https://orcid.org/0000-0001-6415-6977

2 ORCID: https://orcid.org/0000-0002-2230-4393

3 ORCID: https://orcid.org/0000-0003-1366-8651

4 ORCID: https://orcid.org/0000-0002-0780-8120
}

Descritores: Biotecnologia, Saúde Pública, Sistema Único de Saúde, Odontologia em Saúde Pública, Saúde Bucal.

Abstract: This essay intends to discuss issues related to biotechnological practices aiming the improvements aimed of public health services and population needs. One focus of this discussion involves Dentistry and includes the following question: is there a place for this field in the dialogue between biotechnology and public health? According to many authors, it is necessary to analyze the applicability of biotechnological products in dental public health, as well as the guarantee of social and economical relevance related to the advancement of knowledge and application of the results especially relate to the solution of priority health problems and adapting them to the National Policy on Science, Technology and Innovation in Health (NPSTIH) and the National Agenda of Priorities in Health Research (NAPHR). Therefore, the dental community needs to understand and appropriate of this subject considering it represents a challenge for the development of a public oral health, in the largest universal health system in the world.

Key-words: Biotechnology, Public Health, Unified Health System, Public Health Dentistry, Oral Health.

Resumen: Este es un ensayo que analiza aspectos de las prácticas biotecnológicas para ayudar a los servicios de salud pública y las necesidades de la población. El principal objetivo de esta discusión refiere a la Odontología y a la Siguiente pregunta: ¿hay 
lugar para la Odontología en el diálogo entre la biotecnología y la salud pública? Según los autores, existe la necesidad de un análisis de la aplicación de los productos biotecnológicos dentales en la salud pública como también garantizar su pertinencia social y económica, relacionándolos con el avance del conocimiento y aplicando sus resultados, especialmente a la solución de los problemas prioritarios de la salud apuntados por la Política Nacional de Ciencia, Tecnología e Innovación en Salud (PNCTIS) y la Agenda Nacional de Prioridades de Investigación en Salud (ANPPS). En este sentido, la comunidad odontológica debería apropiarse de los conocimientos relacionados con este tema que, en la actualidad, se convierte en un desafío más para la implementación de una salud bucal pública y de calidad en el mayor sistema de salud universal del mundo. Palabras-claves: Biotecnología, Salud Pública, Sistema Único de Salud, Odontología en Salud Pública, Salud Bucal.

\section{Introdução}

Neste ensaio teórico-conceitual, os autores discutem aspectos relativos às práticas biotecnológicas (entendidas como práticas de manipulação de organismos biológicos) em prol de melhorias destinadas aos serviços de saúde pública e às necessidades de saúde das populações. Um dos focos desta discussão orbita ao redor da Odontologia e inclui o seguinte questionamento: há espaço para esta área no diálogo entre biotecnologia e saúde pública? Para isso, fez-se uma busca exploratória na literatura, com descritores, apenas para quantificar a magnitude dessa produção e gerar insights para discussão.

Para isto, o texto está dividido em oito seções que, longe de esgotar o tema, pretende situar, de forma geral o assunto. O caminho percorrido trata desde as formas primitivas do uso de seres vivos para produção de insumos pertinentes à subsistência humana até as possibilidades de manipulação gênica, proporcionada pelo avanço científico e suas implicações ético-sociais.
Por fim, versar-se-á sobre as principais conclusões advindas da reflexão deste tema para prática em saúde pública e para a Odontologia, tentando identificar quais os diálogos possíveis entre esses saberes.

\section{Aspectos conceituais e históricos da Biotecnologia}

O termo Biotecnologia foi usado pela primeira vez em 1919, pelo engenheiro húngaro Karl Ereky e, mais tarde, oficialmente definido na Convenção sobre diversidade biológica, em 1992. A origem da palavra deriva do grego, a partir da combinação dos seguintes radicais: bio (vida), logos (conhecimento) e tecnos (utilização prática) ${ }^{(1)}$.

A Biotecnologia pode ser entendida como uma área que reúne um conjunto de fundamentos teórico-práticos de diversas ciências naturais e da engenharia para aplicação tecnológica a partir do uso de sistemas biológicos e organismos vivos. Trata-se de um produtivo campo de pesquisa e de experimentação que busca construir e/ou modificar produtos ou processos com fins específicos para uso humano ${ }^{(2-4)}$.

Há quem diga que a manipulação técnica de seres biológicos é um fenômeno recente. O homem pré-histórico já se valia de práticas de manipulação de seres vivos em favor de sua subsistência. Exemplos importantes são os siberianos, que extraíam os ossos de mamutes para fabricação de casas que os abrigassem do frio, e os povos indígenas da Nova Zelândia, que desenvolveram uma cultura de exploração de aves cujas plumagens serviam de adorno para esses povos. Ainda, na Síria, mais de 150 espécies de plantas eram domesticadas para fins alimentares e terapêuticos ${ }^{(5)}$.

No que diz respeito à busca por alimento e a possibilidade de exploração do solo para o cultivo, foram observadas mudanças significativas. Em 10 mil anos atrás, o homem andava até $7 \mathrm{~km}$ para extrair seu alimento e, após a revolução agrícola, bastava $1 \mathrm{~km}$ para se atingir o mesmo propósito. Depois da sedentarização e 
domesticação do solo, $1 \mathrm{~km}^{2}$ passou a ser Em meados do século XIX, houve um passo substancial no desenvolvimento da Biologia. Nesta oportunidade, Gregor Mendel conseguiu desvendar os segredos da hereditariedade por meio de cruzamentos com linhagens de ervilhas. A partir deste estudo, foram descritas as características hereditárias como correspondentes a unidades discretas, separadas e recombinadas de diversas maneiras em cada geração que seriam, mais tarde, chamadas de genes. Este foi um dos marcos histórico para a origem e desenvolvimento de uma nova ciência: a Genética $^{(6)}$.

Concomitante ao período correspondente à Segunda Guerra Mundial, os esforços voltaram-se para a produção de antibióticos. Nesta oportunidade, houve destaque para as pesquisas de Chain Florey e os estudos de Fleming, que oportunizaram o descobrimento da penicilina. Neste mesmo período, foi bastante relevante a produção de de, estes pesquisadores construíram um gene que agregava elementos do DNA bacteriano associado ao DNA da espécie Xenopus laevis. Isso marcou decisivamente a "era da engenharia genética", que tinha como objeto de pesquisa o melhoramento genético e desenvolvimento de novas variedades ${ }^{(6)}$.

Em face deste entusiasmo científico, foi sendo construída uma ciência capaz de aprofundar o conhecimento que antes não poderia ser consolidado, seja pelos recursos limitados ou pela falta de incentivo à pesquisa. Desencadeava-se, assim, a Era da Biotecnologia. Enquanto ciência multidisciplinar, a Biotecnologia passou a integrar diversas áreas do conhecimento, como a Biologia molecular, Genética clássica, Microbiologia, Química, Biofísica, Direito e a Filosofia (8). Além disso, reuniu as Engenharias, em especial a Engenharia Química, que é considerada insubstituível no estudo de bioprocessos, como na indústria de fármacos, de alimentos e de petróleo. Integrou-se também a Engenharia da Computação (Bioinformática), que tem sido utilizada para desenvolver programas de base suficiente para alimentar até 100 pessoas ${ }^{(5)}$. muitos aminoácidos e vitaminas ${ }^{(4)}$.

Guardado o devido "salto histórico", na contemporaneidade, com o avanço científico na identificação do DNA realizada por Avry MacLeod e MCarty, em 1944, e na descoberta da estrutura helicoidal do DNA, por Watson e Crick em 1953, tornou-se possível a manipulação da estrutura bioquímica da célula. É importante mencionar que o empenho destes pesquisadores revolucionou a genética e garantiu um avanço surpreendente que acelerou a descoberta da estrutura fina do DNA, possibilitando, assim, o aprofundamento da pesquisa científica com foco na busca do "segredo da vida" $\mathrm{e}$ aspiração de uma "replicação artificial" às vistas ${ }^{(7)}$.

Vale mencionar que a primeira transformação gênica obtida com sucesso foi registrada em 1973, por meio dos estudos de Hebert Boyer e Stanley Cohen, na Califórnia. Nesta oportunida matemática, capazes de dar conta dos desafios do sequenciamento genético e tentam descrever a relação entre genes e proteínas (proteoma), chave para a compressão dos processos vitais $^{(9)}$.

Fato é que, atualmente, existe a real capacidade desenvolvida pelo ser humano em realizar a manipulação a nível molecular e isso gera a oportunidade de intervenção na origem de alguns problemas de saúde, até então, sem solução no âmbito da medicina clínica. Contudo, a drenagem desses esforços para os reais problemas de saúde que afligem as populações (doenças negligenciadas, por exemplo) ainda amargam um desinvestimento notório ${ }^{(10)}$. $\mathrm{O}$ incentivo às pesquisas por parte do Estado nesta área e o evidente conflito entre as prioridades econômicas e sanitárias podem ser considerados os principais pontos que emergem como desafios atuais da Biotecnologia brasileira na produção e reprodução artificial da vida ${ }^{(11),(12)}$.

Sendo assim, no estágio histórico de desenvolvimento científico vigente, pode-se afirmar que há uma forte emergência da Biotecnologia como fonte de esperanças para 
a elaboração de soluções terapêuticas inovadoras. Essas novas perspectivas podem, certamente, revolucionar a prestação de serviços de saúde, em especial, quando se pensa em saúde pública, como pode ser visto no incremento de pesquisas que relacionam descobertas inovadoras no campo biotecnológico e suas aplicabilidades neste tipo de prestação ${ }^{(13)}$. Portanto, para melhor compreensão do tema, faz-se necessário um aprofundamento no significado econômico e social das inovações tecnológicas e sua dinâmica em sociedades capitalistas.

\section{Inovação Tecnológica, Sistema de Inovação e sua aplicabilidade na saúde.}

A tecnologia contemporânea tem sido caracterizada, sobremaneira, pelo desenvolvimento e aplicação da ciência experimental. Neste sentido, de acordo com o recorte temporal e o tipo de cultura, podemos apresentar detalhes acerca do processo de desenvolvimento científico e disponibilização de tecnologias. Em se tratando da temática Tecnologia, podemos considerá-la como sendo o "campo de conhecimento que faz referência ao desenho de artefatos e à planificação da sua realização, operação, ajuste, manutenção e monitoramento, à luz do conhecimento científico" (14).

A partir da incorporação tecnológica junto ao nosso cotidiano, é possível evidenciar a existência de dispositivos que nos fornecem produtos, ou seja, bens e serviços de interesse comum. Desta forma, o avanço científico e a sua aplicação ditam o processo de invenção e inovação tecnológica. $\mathrm{Na}$ área da saúde, este tipo de investimento em avanços e em novas descobertas tecnocientíficas é, cada vez mais, crescente. Novos medicamentos, vacinas, hormônios, enzimas terapêuticas, equipamentos e recursos para fins de diagnóstico e intervenção clínica, implantes, transplantes e, inclusive, a produção artificial de células humanas, são exemplos de campos de investimento e trabalho de técnicos e cientistas (14). Sendo assim, devem ser incorporados critérios específicos que possam garantir a utilização racional desta tecnologia no nosso cotidiano.

Em meio a esta discussão, vale comentar que os termos invenção e inovação não são sinônimos como possa meramente aparentar. Neste campo de conhecimento, a invenção é a ideia original que pode ser uma reformulação de um conceito científico ou até mesmo um aspecto prático de uma teoria. A inovação, trata-se de uma invenção com um uso prático agregado, que pode ser materializada em um produto, processo ou serviço com um potencial comercial definido e que possa ser explorado economicamente (15-17).

Invenções nem sempre viram inovações. Empresarialmente falando, setores comerciais privados chamam de Pesquisa \& Desenvolvimento (P\&D) as áreas responsáveis pelo fluxo operativo (transição) de invenções para inovações. Essa transição não é fácil nem rápida. Em Sistemas de Produção ditos "lineares", em que não há concomitância entre a pesquisa, o desenvolvimento, o marketing, e a produção; a tendência de transformação de invenções em inovações é lenta e, até que se alcance um produto com potencial de mercado, pode-se levar 20 anos ou mais ${ }^{(16)}$.

Em saúde, a inovação pode ser entendida como o processo, produto ou serviço que pode ser incorporado na dinâmica do setor de serviços de saúde. Para que seja fomentada, é necessário o estímulo ao processo inovativo, geralmente dependente do movimento incentivador dos Sistemas de Inovação. Pode-se dizer que o setor saúde dispõe de um Sistema de Inovação em Saúde que ajuda as empresas e entidades públicas (Universidades, Agências, Fundações e outros agentes econômicos) a desenvolverem seu potencial inovador ${ }^{(17)}$. Recentemente, a lei 13.243 de 11 de janeiro de 2016, que regula o desenvolvimento científico-tecnológico e o processo de inovação, em seu artigo $2^{\circ}$., inciso XIII, se refere a utilização do poder de compra do Estado como forma de ir mais além da lógica puramente de mercado que drena a inovação para alguns nichos 
específicos.

Do ponto de vista conceitual, Sistemas de Inovação em Saúde podem ser definidos como sendo o conjunto de instituições distintas (atores sociais) que contribuem para o desenvolvimento e difusão de tecnologias apoiadas na geração de inovações. Estas podem ser advindas não apenas das empresas, mas de todo o universo de organizações e instituições políticas envolvidas nesse processo. Para esses autores, as inovações podem ser classificadas em dois tipos: as inovações incrementais, que são oriundas de pequenas modificações e/ou agregações relacionadas ao melhoramento ou aperfeiçoamento de produto/processo/serviço em questão; e as inovações radicais, que geram um produto inteiramente novo, ou seja, que produzem uma ruptura na pesquisa/produção do produto anterior $\mathrm{e}$ inicia o que diversos autores chamam de uma nova "trajetória tecnológica"(15).

Similarmente às ideias de Thomas Kuhn e sua noção de paradigma, Christopher Fremann explica que esses novos produtos originam um novo "paradigma tecnoeconômico", capaz de modificar toda matriz de produção impulsionada pela promessa de maiores lucros com menores custos associados ao processo. Para exemplificar melhor, foi o que, em décadas atrás, viu-se ocorrer com a emergência da microeletrônica, tida como um novo paradigma tecnoecônomico após a crise da matriz energética mundial à base de petróleo, em 1970-1974 ${ }^{(18-20)}$.

Neste aspecto, o crescimento das indústrias e o próprio acúmulo de capital ameaçado promoveram a reformulação do processo produtivo em prol de um avanço industrial de outra ordem tecnológica. Não obstante, é possível perceber a interação que diversos setores sociais (indústrias, Estado, setor privado, universidades, só para citar alguns) tiveram que fazer para reordenar a produção em uma nova trajetória, o que caracteriza bem a dinâmica do processo inovativo e a necessidade de constante interação entre os agentes econômicos do sistema. Em saúde, o Sistema de Inovação tem se caracterizado pela consolidação de um Complexo Econômico-Industrial da Saúde, que por sua vez sustenta o processo inovativo nos moldes de um sistema capitalista fechado de produção, como será explicitado a seguir (15).

\section{Biotecnologia aplicada à saúde pública: o seu lugar no Complexo Econômico- Industrial da Saúde (CEIS)}

Em uma conceituação mais elaborada, admite-se que Biotecnologia é a exploração tecnológica da biodiversidade em prol da resolução de problemas da saúde humana ${ }^{(5)}$. Quando essa atividade está direcionada às necessidades de saúde das populações, orientando suas práticas à preservação/manutenção das sociedades (21), pode-se dizer que estamos falando da Biotecnologia aplicada à saúde pública, ou resumidamente, Biotecnologia em saúde pública $^{(22),(23)}$.

Com efeito, a robustez teórica deste conceito depende da apropriação de alguns termos-chave que estão diretamente associados ao que se entende por "Biotecnologia" e "Saúde Pública", respectivamente. $\mathrm{O}$ primeiro deles, associado à prática biotecnológica, está o conceito de "biodiversidade". Entende-se por biodiverso aquele ambiente em que há uma pluralidade de seres vivos (plantas, animais, microorganismos, etc.) representando uma variabilidade de genes, de espécies e de habitats ${ }^{(5)}$. Ao segundo, resultante da prática sanitária, está o conceito de "risco", este pode ser entendido como a probabilidade da ocorrência de determinado evento relacionado à saúde de uma população, estimado a partir do que ocorreu em seu passado recente ${ }^{(22)}$.

A relação entre esses conceitos é extremamente pertinente, pois denota a capacidade que a Biotecnologia, quando aplicada à saúde pública, é capaz de gerar alterações na diversidade biológica em uma escala considerável, incutindo riscos de grande magnitude à saúde humana se não realizada dentro de padrões eticamente 
aceitáveis. Em que pese à relevância dessa discussão, trataremo-la em momento oportuno nesse texto e, por enquanto, focaremos no local subsetorial no qual a Biotecnologia se insere nesse cenário econômico-industrial ${ }^{(17)}$.

No que diz respeito a este quesito, é importante comentar um fenômeno marcante observado na área da saúde nos últimos sessenta anos: a desmercantilização do acesso à saúde e a mercantilização da oferta/provisão. Isso está diretamente relacionado com a criação de um parque industrial considerável, ligado à área. Dentre todos os seus principais representantes, podemos citar as indústrias de base química e biotecnologia, mecânica, eletrônica e de materiais (24), (25). Atualmente, essas grandes indústrias que atuam no setor, compõem o chamado Complexo Econômico-Industrial da Saúde (26). Trata-se de um processo de formação recente e altamente dependente da inovação tecnológica e do próprio avanço científico no campo biomédico ${ }^{(25)}$.

\section{Conceitualmente falando,}

O

\section{Complexo Econômico-Industrial da Saúde} se trata de uma divisão do processo de trabalho entre agentes econômicos (em especial, indústrias e organizações prestadoras de serviços) que, sob forte interação entre si, movimentam a compra e venda de bens/serviços, trocam conhecimentos/tecnologias, celebram acordos comerciais, normas de conduta e perfil de comportamento de mercado ${ }^{(15)}$.

Dentre os elementos que compõem esse complexo, tem-se: os setores industriais representados pelas indústrias de base química e biotecnológica e pelas indústrias de base física, mecânica e eletroeletrônica; e; as organizações prestadoras de serviços de saúde (hospitais, ambulatórios e serviços especializados) (26),(27). Nesta configuração, pode-se dizer que o fazer biotecnológico se encontra localizado nas indústrias de base químico-biotecnológicas desse complexo orgânico e articulado.

As indústrias de base químicobiotecnológicas são fortemente representadas pelas corporações farmacêuticas, que detêm a maior fatia do mercado internacional e é constituída por um oligopólio de 10 empresas que dominam o cenário mundial ${ }^{(15)}$. Logo em seguida, encontram-se as indústrias produtoras de vacinas, que, no Brasil, são caudatárias da intervenção Estatal para produção de imunobiológicos, e que, aos poucos, vem obtendo autossuficiência na produção desses insumos ${ }^{(28)}$. É pertinente lembrar a celeuma existente no Brasil, relacionada aos conflitos de interesse entre as prioridades sanitárias, políticas e econômicas nos incentivos à produção desses insumos ${ }^{(11)}$.

Uma atividade estatal de saúde pública que fomentou o investimento nesses insumos foi o Programa Nacional de Imunização (PNI). Criado em 1973, angariou recursos para emancipação técnico-financeira do país frente à importação de vacinas. Para isso, recursos foram injetados em Instituições com expertise na área (como a Biomanguinhos/Fiocruz no Rio de Janeiro e o Instituto Butantã em São Paulo) com vistas a abastecer a rede pública de saúde com esses insumos fundamentais. Outros produtos de origem biotecnológica, mas ainda sem grande expressão econômica, são os soros e as toxinas, como veremos com mais detalhes na seção que se segue ${ }^{(10),(11)}$.

\section{Os principais insumos da prática biotecnológica em saúde pública}

Os principais insumos derivados das práticas biotecnológicas aplicados à saúde pública são as vacinas, os soros e as toxinas (17). A maior parte dos insumos originados pela manipulação biológica de seres vivos é baseada no uso de microorganismos destinados à síntese de novas moléculas que se utilizam de seus ciclos bioquímicos. $\mathrm{O}$ custo associado à síntese puramente química de moléculas tem sido muito alto, especialmente, devido ao emprego de altas taxas de energia e tempo que só podem ser alcançados por meio do uso de potentes equipamentos laboratoriais (como ultracentrífugas, por exemplo) (28). Resumindo, pode-se dizer que as sínteses 
químicas encarecem os processos de produção de insumos, cujas etapas de produção de moléculas finais ou intermediárias podem ser substituídas por sínteses de origem microbiana.

$\mathrm{Na}$ prática, ainda persiste uma simbologia espraiada no ideário social de que a biodiversidade disponível na natureza (principalmente, quando o país dispõe de uma Floresta Amazônica) é o suficiente para esgotar as possibilidades de produção biotecnológica com foco na cura de doenças. De forma mais clara, não é tão incomum deparar-se com sujeitos com algum grau de capital cultural apostando na descoberta de uma substância extraída de uma espécie, até então, 'desconhecida' que servirá para o tratamento de uma doença incurável qualquer. Ao contrário disso, mesmo a biodiversidade do país sendo reconhecidamente um potencial a ser explorado, os avanços atuais na área que já apresentam uso em saúde pública repousam em grande parte no uso de microorganismos para fabricação de insumos biotecnológicos ${ }^{(10),(11)}$.

Alguns autores $^{(10),(11)}$ já identificaram três tendências de pesquisas que estão se consolidando no país no âmbito da aplicação da biotecnologia em saúde pública. Primeiramente, as pesquisas dirigidas ao uso de terapia celular na cura de doenças degenerativas, como nos casos relacionados aos linfomas e os transplantes de medula óssea como experiências bem-sucedidas nesse âmbito. Pesquisas nesse ramo, orientadas ao tratamento de diabetes tipo I, estão sendo fomentadas. As principais inciativas vão desde a produção de insulina NPH, a partir da estrutura molecular de porcos, até $\mathrm{O}$ desenvolvimento de biomateriais para imunoisolamento nos casos de transplantes de Ilhotas de Langerhans.

Em segundo lugar, está a pesquisa com foco no Projeto Genoma Humano, em especial, no estudo de marcadores tumorais. Nesta seara, o conhecimento da estrutura celular de seres vivos mais simples (como bactérias, por exemplo), permite o mapeamento gênico de doenças e o sequenciamento dessas expressões em humanos. Além disso, a análise de produtos gênicos ajuda na obtenção de seqüências, na descoberta de vetores de transferências, de sistemas-modelos e de linhagens celulares adequadas. Essas descobertas têm tido grande repercussão na identificação de genes reguladores do câncer de próstata e nas bases moleculares dos cânceres de cabeça, pescoço e tireóide.

Em terceiro, apresentam-se as pesquisas com biofármacos aplicados à medicina, odontologia e veterinária. Nesta área, estudos têm sido desenvolvidos objetivando identificar na fauna e na flora moléculas que são precursoras de princípios ativos de medicamentos ou de biomateriais utilizados em procedimentos cirúrgicos (como as membranas ósseas, BMP, dentre outros). Além disso, investimentos na pesquisa de fatores de coagulação (como o fator VIII e IX) têm sido impulsionados como forma de dirimir a dependência brasileira dos bancos de sangue externos e dos hemoderivados importados, principalmente para o tratamento da hemofilia e da Doença de Von Willembrand.

\section{Relevância dos insumos biotecnológicos para a saúde pública e suas implicações na organização dos serviços}

Recentemente, a introdução dos produtos biotecnológicos nos serviços de saúde pública tem alcançado avanços significativos. Pelo menos quatro destes são dignos de nota. Em primeiro lugar, vale mencionar a introdução do captopril como um hipotensor desenvolvido a partir do peptídeo presente no veneno da serpente Bothrops jararaca (BPF-bradkinin-potentiating factor), após a descoberta da propriedade vasodilatadora da bradicinina (substância presente na sua composição) ${ }^{(10),(11),(28)}$. Podemos citar, ainda, o desenvolvimento do catálogo vacinal do SUS, por meio do aumento do número de produtos imunobiológicos e da busca da autossuficiência da capacidade produtiva de vacinas destinadas a prevenção de diversas 
doenças, em especial, as últimas aquisições (rotavírus humano e influenza sazonal) advindas das recentes pesquisas do uso de vírus atenuados ${ }^{(12),(28)}$; a produção de insulina $\mathrm{NPH}$ (já descrita anteriormente), que abastece a rede pública de saúde, detendo a maior distribuição gratuita realizada por um programa de atenção à diabetes existente no país ${ }^{(29)}$; e, por último, a produção de fitoterápicos para uso no SUS como alternativa à farmácia alopática em algumas regiões do país, nas quais 71 espécies constam na lista da RENISUS ${ }^{(30)}$.

Contudo, é possível perceber que uma nova ordenação dos serviços públicos de saúde vem se configurando após a introdução das práticas de saúde baseadas em produtos biotecnológicos, se fundamentando, especialmente, no uso dos fitoterápicos. No bojo da discussão sobre os questionamentos a respeito dos processos de cuidado da medicina ocidental e, consequente crítica ao modelo biomédico de atenção ${ }^{(31)}$, a adoção de fitoterápicos como método alternativo (e, por vezes, substituto) do medicamento sintético, veio ganhando adeptos. Não obstante, em 2006, o Ministério da Saúde promulgou a Política Nacional de Práticas Integrativas e Complementares (PNPIC) com o intuito de institucionalizar o uso de diversas formas alternativas de exercício da prática/técnica em saúde no âmbito do SUS ${ }^{(32)}$. Mesmo sob uma leitura rápida, é evidente a ênfase que o documento propõe a respeito do uso de fórmulas fitoterápicas e criação de laboratórios de fitoterapia orientados para práticas sanitárias no sistema público de saúde.

Outro aspecto reorganizador importante tem sido o incentivo da Secretaria de Ciência, Tecnologia e Insumos Estratégicos ao formular as Agendas Nacionais de Prioridades de Pesquisa em Saúde (ANPPS) ${ }^{(33)}$. Essas agendas vislumbram o realinhamento de interesses econômicos na exploração de produtos biotecnológicos e a necessidade das demandas sanitárias das populações ${ }^{(17)}$. Outra estratégia lançada pelo Departamento de
Ciência e Tecnologia (DECIT) da mesma Secretaria trata da criação da Estratégia Nacional de Biotecnologia, em 2004 ${ }^{(34)}$. Nesta, a proposta reside em fazer as indústrias focarem sua produção em quatro áreas: vacinas; biomateriais; hemoderivados; e kits de diagnósticos. Essa produção é destinada a atender a expectativa pública e, em certa medida, vem aumentando o acesso da população usuária do serviço público a esses produtos em virtude de sua disponibilidade no SUS, mesmo alguns autores afirmando que ainda está longe de se garantir a cobertura universal por esses serviços ${ }^{(10)}$.

Finalmente, no âmbito da reorganização dos serviços públicos, é importante ressaltar que a inserção dos produtos biotecnológicos (tomando o caso dos fitoterápicos apenas como um exemplo) geram mais demanda para o próprio SUS, se transformando em demandas regulatórias e fiscalizatórias para os serviços de vigilância sanitária e ambiental ${ }^{(35)}$. Sendo assim, esses serviços passam a dispor de mais um rol de itens de risco sanitário que merecem sua $\operatorname{atenção~}^{(36)}$.

\section{Biotecnologia aplicada à Odontologia: onde está a saúde pública?}

Como visto anteriormente, alguns autores $^{(13)}$ já registravam o avanço da biotecnologia enquanto campo disciplinar no âmbito da produção acadêmica. No entanto, em uma pesquisa exploratória na base de dados do portal Bireme, sem filtro de idioma e de período, considerando manifestações do termo no título, resumo e assunto, utilizou-se o descritor "biotecnologia" como descritorfixo e cruzando com descritor "saúde". Foi possível perceber que, nos últimos 30 anos, um pouco mais de 2.900 estudos (dentre eles, publicações técnico-científicas como artigos, teses e dissertações e publicações de base técnico-normativa como manuais, resoluções, etc.) foram encontrados. Ao trocar o descritor "saúde" pelo descritor "saúde pública", esse número se reduz a menos de um décimo (244 estudos) do anteriormente encontrado, o que revela (aproximadamente) que pequena parte 
dos estudos de biotecnologia são/estão relacionados à aplicação de soluções em saúde pública.

A combinação do descritor-fixo "biotecnologia" com o descritor "odontologia" resultou em 42 estudos, onde nenhum desses dialogam diretamente com a saúde pública. Diversos são os temas abordados nessas pesquisas, mostrando as potenciais aplicações na odontologia como: implantologia, terapia genética e regeneração tecidual e materiais odontológicos, além de bioética e biossegurança. $O$ fato é que a Odontologia, apesar da robusta produção científica, tem despertado pouca atenção à interface Biotecnologia/Saúde Pública como campo de pesquisa. Isso pode estar relacionado com a falta de interesse de estudo nesta área de concentração, pouco conhecimento acerca de sua aplicação na Odontologia ou mesmo falta de recursos apropriados para a operacionalização de experimentos sofisticados. $\mathrm{Ou}$, pode-se refletir ainda, sobre a pouca possibilidade (político-econômica) de aplicar estes conhecimentos atendendo a necessidade de saúde bucal da população brasileira.

Em estudo realizado por pesquisadores na área de saúde bucal acerca das tendências da produção científica em Odontologia no Brasil, foi constatado que esta categoria experimentou um salto significativo nos primeiros anos do século XXI, expresso pela maior divulgação em revistas especializadas e por apresentações em encontros científicos. Contudo, esse crescimento não foi necessariamente acompanhado por uma melhoria na qualidade das publicações. Isso se justifica pelo fato de que algumas destas publicações apresentam interpretação errônea de dados, análise equivocada de associações estatísticas e, até mesmo, a ocorrência de problemas elementares no que tange à produção textual $^{(37)}$.

Em linhas gerais, quanto ao desenho metodológico, houve predomínio dos estudos de natureza individuada, típicos de pesquisas com enfoque clínico, para o estudo de materiais e com impacto limitado, mas não excludente, para as coletividades humanas. Das 5.203 publicações, 87,5\% envolviam estudos com este tipo de perfil. Houve, ainda, predomínio discreto dos estudos de natureza intervencionista sobre os observacionais, e dos estudos longitudinais sobre os transversais. No que diz respeito à área de conhecimento, foi observado maior número de ocorrências de pesquisas nas áreas da dentística, da periodontia, da endodontia e da odontopediatria. Neste mesmo estudo, foi dado um destaque significativo à área de conhecimento da saúde bucal coletiva, que correspondeu à quinta área com maior produção dentre 19 especialidades. Por fim, quanto à natureza geral, foi constatada maior frequência de estudos laboratoriais $(54,7 \%)$, quando comparados a estudos em humanos (30,2\% das publicações relacionadas a pesquisas clínicas e, 11,5\%, pesquisas com sujeitos coletivos) e revisões bibliográficas $(3,6 \%)^{(37)}$.

Atualmente, há uma tendência diferenciada que está sendo observada em relação a este cenário de publicação. É notório que a saúde bucal coletiva continua sendo temática de interesse dos pesquisadores. Isso se justifica pela consolidação das políticas públicas atuais que giram em torno desta linha de produção acadêmica. Contudo, há crescimento discreto que pode ser observado, também, em pesquisas experimentais e laboratoriais. Assim, mesmo diante dos modestos investimentos em pesquisa no país, comparando-se com economias similares ${ }^{(38)}$, alguns centros acadêmicos (UFAM, UFPE, UFPA, UFMG, UFSC) ${ }^{(39)}$ têm destinado interesse nessa área, especialmente, por meio de grupos e linhas de pesquisa com foco em Biotecnologia aplicada à Odontologia.

Vale comentar que os avanços na ciência, como a biologia molecular, por exemplo, e nas tecnologias geradas nos últimos anos, possibilitou a utilização de novos aparatos tecnológicos na promoção, prevenção, diagnóstico precoce, tratamento e reabilitação do dano em diversas especialidades desta área e relacionados a um 
grande número de patologias ${ }^{(40)}$. Este tipo de avanço, embora seja pouco acessível, tem orientado uma postura diferenciada do cirurgião-dentista. Isso se justifica pelo fato de que, hoje, seria possível saber, por exemplo, se $\mathrm{o}$ paciente tem uma predisposição genética a desenvolver determinada patologia, como a cárie dentária, problemas periodontais ou reabsorções radiculares. Para isso, poderiam ser utilizadas técnicas de estudo a partir do DNA das células da mucosa epitelial da boca, que consistiria em uma ferramenta de grande valia no cotidiano do consultório ${ }^{(40)}$.

Em um publicado em 2002, mais um passo importante foi dado em relação à Odontologia. O genoma do Streptococcus mutans foi sequenciado por pesquisadores da Universidade de Oklahoma e divulgado por meio de artigo intitulado "Genome sequence of Streptococcus mutans UA159, a cariogenic dental pathogen". Tal publicação foi promissora e poderá subsidiar novos estudos e fornecer bases para a prevenção e tratamento da doença cárie ${ }^{(41)}$ em nível celular e molecular.

Dentre outras pesquisas mais notórias utilizando conhecimentos de outras áreas das ciências da saúde estão o uso da copaíba como antiinflamatório em lesões bucais e tratamentos endodônticos ${ }^{(42),(43)}$ e o uso da papaína em lesões cariosas agudas ${ }^{(44)}$. Uma nova vertente voltada para a pesquisa em biomateriais também vem esboçando fôlego como, por exemplo, o gel de bromelina em restaurações dentárias ${ }^{(45)}$ e as investigações sobre o uso do cimento Portland como material obturador de canais radiculares e como consolidador de fraturas ósseas mandibulares em ratos ${ }^{(46)}$.

Os estudos com células-tronco e a reprodução de tecidos dentais têm despertado interesse de alguns grupos de pesquisa que visam a reprodução do elemento dental completo, com fins de reabilitação dentária gênica (ou terceira dentição) ${ }^{(47)}$. Trata-se de uma área de pesquisa intitulada Bioengenharia. Em Odontolgia, inúmeros estudos têm isolado células altamente proliferativas, derivadas da polpa dentária, e constatado que podem manifestar características diversas como a capacidade de auto-renovação e de diferenciação em diversos tipos celulares ${ }^{(48),(49)}$.

Em se tratando da especialidade de Periodontia, que trata do órgão dentário e suas estruturas de suporte e proteção, também podem ser observados estudos relevantes, principalmente, quando a temática envolve a regeneração periodontal. Ao investigar tais estruturas, alguns pesquisadores demonstraram a presença de células troncoadultas no ligamento periodontal, com propriedade clonogênica e alta taxa proliferativa $^{(50)}$. Na tentativa de promover a diferenciação destas células em cementoblastos, foi utilizado um meio rico em L-ascor-bato-2 fosfato, dexametasona e fosfato inorgânico, in vitro, e, após 4 semanas, foi observado discreto nível de acumulação cálcica. Contudo, a proporção deste nível cálcico por estas células, comparada com as células-tronco provenientes da medula óssea e da polpa dentária, foram menores.

Outra estratégia adotada na Biotecnologia é a utilização dos fluidos corporais como método de diagnóstico. O uso da saliva, por exemplo, avançou significativamente nos últimos anos. Foram mais de 2.000 artigos escritos referentes a testes salivares realizados desde 1982, descrevendo o uso de saliva no monitoramento de doenças sistêmicas e bucais $^{(51)}$. Uma das vantagens na utilização deste fluido para o diagnóstico em substituição ao sangue, é o acesso fácil à boca, com coleta não-invasiva. Diante desta explicação, a saliva tem sido apontada como um líquido biológico potencial para testes diagnósticos.

Sabe-se que a avaliação bacteriana em amostras salivares constitui ferramenta realmente importante na identificação precoce de indivíduos com alto risco biológico para o desenvolvimento da cárie dental. Aliada a isso, a atividade da doença cárie pode ser avaliada de maneira complementar. Em que 
pese a sua especificidade epidemiológica, o índice CPO-D (Índice de Dentes Permanentes Cariados, Perdidos por Cárie ou Obturados) poderia ser utilizado, como também a investigação da dieta alimentar. Assim, testes salivares para a identificação de elementos intimamente relacionados com o risco de cárie estão sendo propostos, buscando alcançar a praticidade necessária para a saúde bucal. Recentes trabalhos publicados indicam que lectinas vegetais possuem potencialidade importante como um possível insumo biotecnológico a ser utilizado em programas de prevenção de cárie e de doença periodontal $^{(52),(53)}$.

Ainda considerando a Biologia Molecular como base de pesquisa, alguns autores relatam, em estudos recentes, a relação entre a agenesia dentária e a função anormal de genes específicos, que seriam elementos-chave durante a fase de odontogênese. Dentre os genes associados, estão o $M S X 1$ e o $P A X^{(54)}$. Isso tem sido considerado bastante relevante para o clínico, uma vez que poderiam ser lançadas estratégias de investigação desde cedo e buscadas alternativas plausíveis para a minimização do dano. Uma das alternativas propostas pelos autores supracitados teria base na análise de DNA. Assim, poderiam estar disponíveis e acessíveis tecnologias diferenciadas para os profissionais de saúde, resultando em um diagnóstico mais preciso e permitindo uma melhor abordagem a esta anomalia. Desta forma, estudos sobre a expressão gênica poderiam ser valiosos para esclarecer a patogênese da agenesia dentária.

\section{Algumas implicações socio-éticas das práticas biotecnológicas em saúde pública nas sociedades}

Quando se fala em biotecnologia aplicada à saúde pública, é inevitável a reflexão a cerca das estratégias e intervenções maciças que estão sendo empreendidas nas populações com base em produtos obtidos de seres "bioengenharizados". Ao passo que o uso de insumos biotecnologicamente desenvolvidos aumenta, é impossível não atentar às consequências que essa prática pode provocar na vida dos seres humanos, já que os organismos (microorganismos, animais, vegetais, fungos etc) são seres biológicos como outros quaisquer.

Baseado no apelo ao "risco", a saúde pública (compreendida como uma ação humana interventiva) parte para perpetuar o que na natureza não se apresenta com "risco" e a eliminar/controlar aquilo que nela identifica como tal. Há de se fazer um novo pacto sanitário em prol do desenvolvimento biotecnológico que promova melhoras à saúde pública, mas sem gerar diminuição ou exacerbação artificialista da biodiversidade $^{(55)}$. Com efeito, alguns autores $^{(12)}$ creem que a prática biotecnológica indiscriminada poderá gerar uma estandartização gênica com consequências maléficas à humanidade. $\mathrm{O}$ principal argumento reside na susceptibilidade em que os seres humanos adquiririam pela administração (por vezes compulsória - no caso das vacinas) de organismos biológicos padronizados geneticamente. A interação desses microorganismos com o metabolismo celular humano, se tomado em grande escala (como são, geralmente, as medidas de saúde pública), incorreria em uma uniformização gênica em massa que exporiam os seres humanos a riscos biológicos antes inimaginados.

Em contraponto à versão da "baixa variabilidade gênica" induzida, outros autores $^{(55)}$ apontam que o trabalho biotecnológico transcende a dimensão social e invade a seara ética. Pois, como qualquer outra prática humana, a biotecnologia pode ser considerada como um evento cultural e que ganhará, ao longo do seu desenvolvimento, uma infinidade de formas de ser executada. Partindo-se desse pressuposto, não se deve esperar por uma suposta "regularidade gênica" em massa, mas sim a agudização da diversidade, que, em escalas populacionais consideráveis, geraria a promoção de uma ultradiversidade com a formação de indivíduos híbridos. Nessa perspectiva, se o consumo de produtos 
biotecnológicos for levado às últimas consequências, o processo de hibridização pode, inclusive redefinir ou até destituir o estatuto de humanidade desses seres devido a tamanha mescla genética oriunda dos diversos insumos biotecnológicos aos quais às populações estarão submetidas ao curso de suas vidas.

Para tanto, reflexões profundas devem ser feitas acerca dos riscos que a biotecnologia incute à vida humana quando assumida como prática sanitária. Nessa arena, o que está se pondo em "xeque" são os aspectos filosóficos do ser humano, o que requer empenho entre ciência e sociedade em busca de diálogos promissores para $\mathrm{o}$ enfrentamento dos ônus que a biotecnologia apresenta quando se torna uma práxis de saúde pública.

\section{À guisa de conclusão}

À guisa de conclusão, podemos elencar mais perguntas do que respostas aos desafios deste diálogo tão necessário. Assim sendo, poderíamos identificar como a primeira delas: o que, de fato, tolhe o diálogo entre Biotecnologia e Odontologia visando soluções para a Saúde Pública? Parece que, como em qualquer outra área, o problema reside em converter o conhecimento científico em um produto de utilidade ou em processos inovadores e competitivos.

Essa reflexão nos leva a pensar sobre a origem desses recursos. Do ponto de vista de financiamento, a pesquisa puramente biotecnológica (que não apresente clara aplicabilidade em saúde pública, que não assegure relevância social e econômica relacionada com o avanço do conhecimento ou da aplicação dos resultados à solução de problemas prioritários de saúde ou, ainda, que não contemple a Política Nacional de Ciência, Tecnologia e Inovação em Saúde - PNCTIS e a Agenda Nacional de Prioridades de Pesquisa em Saúde - ANPPS) deve ser financiada pelo Sistema Único de Saúde, em seus editais periódicos como PP-SUS, por exemplo? De certo, não há nada que impeça. Entretanto, é eticamente aceitável comprometer um orçamento público com o financiamento de pesquisas que não assegurem um produto/processo/serviço inovador aplicado ao cotidiano do SUS?

Neste âmbito há quem ache que deva ser patrocinado, já outros acham que não e todos com argumentos válidos. Há quem pense que o patrocínio dessas pesquisas deve vir das empresas privadas haja vista que, do ponto de vista de complexo industrial, elas são as fornecedoras (agente econômico) para o SUS. Entretanto, muitas delas são monopolistas e detém forte influência econômica. Isso torna o SUS mais dependente de sua produção e reforça o argumento contra o financiamento privado dessas pesquisas. Assim, mais uma celeuma da imbricada mescla público-privado emerge e requer que os tomadores de decisão das políticas públicas vigentes estejam atentos aos interesses que permeiam a produção e comercialização da inovação em saúde bucal, cuja filosofia parece longe de uma aplicabilidade em serviços públicos (como se percebe na omissão da literatura científica sobre esse ponto).

Os temas abordados pelas pesquisas de biotecnologia e odontologia poderiam ser de uma importante aplicação para a Política Nacional de Saúde Bucal, que visa atender as necessidades de saúde bucal de toda a população brasileira. É essencial que haja a abertura de um canal político e econômico que aproxime a academia e serviço no sentido de que pesquisas sejam feitas para favorecer esse diálogo.

Diante do exposto, fica a indagação: o que, concretamente, tem virado inovação em odontologia? Que inovações têm sido incorporadas no serviço público? Nesse sentido, é possível falarmos de uma Biotecnologia aplicada à Odontologia que está sendo utilizada nos serviços de Saúde Pública?

Pelo que relata a literatura especializada, crê-se que ainda não. Mesmo sob forte influência das pesquisas laboratoriais, a Odontologia carece de pesado investimento acadêmico na pesquisa 
biotecnológica para a saúde pública. Não se vê o que de fato vira inovação em odontologia e menos ainda o quê disto é disponível na rede de serviços públicos de saúde. É possível especular sobre a invisibilidade que essa falta de aplicação (ou utilização) traz aos centros de pesquisa que não fomentam o diálogo entre Biotecnologia, Odontologia e Saúde Pública. Isso vem demonstrando a despreocupação com a inserção social de suas pesquisas e o alcance de larga escala que os produtos biotecnológicos poderiam ganhar no cotidiano da economia de mercado e, principalmente, na prática de novos modos de se fazer saúde bucal no SUS.

Caso esse diálogo surja, porventura, espontaneamente, ainda assim encontrará entraves no âmbito da prestação dos serviços públicos. Em tempos de crise estrutural do capitalismo financeiro, o que menos se espera é investimento em direitos sociais. Tal fato favorece a disponibilização dos recursos para iniciativa privada e fragiliza a relação biotecnologia/odontologia/saúde pública patrocinada exclusivamente pelo poder público. Como um reforço nefasto, acrescenta-se aí uma "pitada" de legislação que cerceia os direitos, em nome de uma segurança jurídica e estabelece "padrões" de integralidade, como no caso das recémeditadas RENASES e RENAME. Essas listas dificultam a pressão popular via judiciário pelo acesso a bens e serviços sanitários previstos como direitos do cidadão coberto por um sistema de saúde, supostamente integral. Assim, aquilo que poderia ser um produto biotecnológico aplicado à odontologia, apresentará mais uma dificuldade de inserção no rol de insumos a serem consumidos nos serviços públicos de saúde em todo o país.

Mesmo, diante deste cenário pessimista, é necessário lembrar que os Determinantes Sociais de Saúde e as ações que neles incidem (as de Promoção da Saúde) são fundamentais na ausência de ações mais proximais inovadas, ou seja, as ações clínicas que poderiam ser intensificadas caso os insumos biotecnológicos em odontologia fizessem parte do arsenal de tecnologias disponíveis na Estratégia de Saúde da Família assim como o captopril, hoje, o é. Este último e singelo exemplo, como largamente esquadrinhado ao longo desse artigo, só nos demonstra que, esse diálogo, aparentemente biomédico, é tão social quanto qualquer outra pauta. Cabe, portanto, a comunidade odontológica entender e se apropriar do conhecimento relativo a este tema que, na atualidade, é mais um desafio à implantação de uma saúde bucal pública e de qualidade no maior sistema de saúde universal do mundo.

\section{Referências}

1. Cunha CR, Melo MCOL. A confiança nos relacionamentos interorganizacionais: $\mathrm{O}$ campo da biotecnologia em análise. RAE Eletrônica. 2006; 5(2):1-26.

2. Ferro ES. Biotecnologia translacional: hemopressina e outros peptídeos intracelulares. Estud. av. 2010; 24(70):109121.

3. Silva RCM. Um rosto para vestir, um corpo para usar: narrativa literária e biotecnologia. Horiz. antropol. 2008; 14(29):151-188.

4. Grisólia S. A biotecnologia no terceiro milênio. In: Romeo CA, Sabona CM. (Org.). Biotecnologia, direito e bioética: perspectivas de direito comparado. Belo Horizonte: Del Rey, 2002. p. 16-22.

5. Garcia ES. Biodiversidade, biotecnologia e saúde. Cad. Saúde Pública. 1995; 11(3):495500 .

6. Borém A. A história da Biotecnologia: a ciência que está surpreendendo até os mais otimistas. Biotecnologia, Ciência \& Desenvolvimento. 2005; 34:10-12.

7. Ortiz LC. A fantástica descoberta da estrutura do DNA faz 50 anos. Cienc. Cult. 2003; 55(2):22-22.

8. Trigueiro MGS. O clone de Prometeu: a biotecnologia no Brasil: uma abordagem para a avaliação. Brasília: Universidade de Brasília; 2002.

9. Arbix G. Biotecnologia sem fronteiras. Novos 
estudos - CEBRAP. 2007; 78:5-10.

10. Morel C. Revolução na biotecnologia e inovação em saúde: situação do Brasil frente ao panorama internacional. In: Scivoletto $\mathrm{R}$, Camargo AC. (orgs). Inovação, Biotecnologia e Saúde Pública. São Paulo: Instituto UNIEMP, 2005, p. 11-29.

11. Sogayar M.C. Avanços na biotecnologia e aplicações na saúde. In: Scivoletto $R$, Camargo AC. (orgs). Inovação, Biotecnologia e Saúde Pública. São Paulo: Instituto UNIEMP, 2005, p. 61-78.

12. Mendonça-Hagler LCS. Biodiversidade e biossegurança. Revista Biotecnologia, Ciência e Desenvolvimento. 2001; 8:16-22.

13. Luz MT, Mattos RS. Dimensões qualitativas na produção científica, tecnológica e na inovação em Saúde Coletiva. Ciênc. saúde coletiva. 2010; 15(4):1945-1953.

14. Lorenzetti $\mathrm{J}$ et al . Tecnologia, inovação tecnológica e saúde: uma reflexão necessária. Texto contexto - enferm. 2012; 21(2):432-439.

15. Gadelha CAG, Maldonado JMSV. Complexo Industrial da Saúde: dinâmica de inovação no âmbito da saúde. In: Giovanella, L. et al (org.). Políticas e Sistemas de Saúde no Brasil. Rio de Janeiro: Editora Fiocruz, 2008, p. 247-281.

16. Gadelha, C.A.G. Dinâmica dos investimentos no subsistema de base química e biotecnológica. In: ___ A dinâmica do sistema produtivo da saúde: inovação e complexo econômico-industrial. Rio de Janeiro: Editora Fiocruz, 2012, p. 47-104.

17. Viana ALD, Nunes AA, Silva HP. Complexo produtivo da saúde, desenvolvimento e incorporação de tecnologias. In: Ibañez N, Elias PEM, Seixas PHD. Políticas e Gestão Pública em Saúde. São Paulo: Hucitec: Cealag, 2011, p. 75-101.

18. Kuhn T. A estrutura das revoluções científicas. São Paulo: Perspectiva, 1991.

19. Fremann C. Technology, Policy and Economic Performance: lesson from Japan. Londres: Pinter Publishers, 1987.

20. Hobsbawm E. Era dos extremos: o breve século XX 1914-1991. Companhia das Letras: São Paulo, 1995.

21. Ianni AMZ. Biodiversidade e Saúde Pública. Saúde e Sociedade. 2005; 14(2):77-88.

22. Luiz OC, Cohn A. Sociedade de risco e risco epidemiológico. Cad. Saúde Pública. 2006; 22(11):2339-2348.

23. Ianni AMZ. Biotecnologia, biodiversidade e risco na saúde. ANPPS, 2010. p. 1-17.

24. Viana AL, Silva HP, Elias PEM. Economia política da saúde: introduzindo o debate. Divulgação em Saúde para Debate. 2007; 37:7-20.

25. Viana ALD, Elias PEM. Saúde e desenvolvimento. Ciênc. saúde coletiva. 2007; 12(Sup.0):1765-1777.

26. Gadelha CAG. O complexo industrial da saúde e a necessidade de um enfoque dinâmico na economia da saúde. Ciênc. Saúde Coletiva. 2003; 8(2):521-535.

27. Gadelha CAG. Desenvolvimento, complexo industrial da saúde e política industrial. Rev. Saúde Pública. 2006; 40(N.Esp):11-23.

28. Raw I. Biotecnologia e Saúde Pública. Revista USP. 2007; 75:6-17.

29. Silva TR. et al. Controle de diabetes Mellitus e hipertensão arterial com grupos de intervenção educacional e terapêutica em seguimento ambulatorial de uma Unidade Básica de Saúde. Saude soc. 2006; 15(3):180189.

30. Júnior, JMN et al. Política Nacional de Medicamentos Fitoterápicos - Desafios e perspectivas. RAHIS. Revista de Administração Hospitalar e Inovação em Saúde. 2010; 4:42-29.

31. Rios ERG. et al. Senso comum, ciência e filosofia: elo dos saberes necessários à promoção da saúde. Ciência e Saúde Coletiva. 2007; 12(2):501-509.

32. Brasil. Ministério da Saúde. Secretaria de Atenção à Saúde. Departamento de Atenção Básica. Política Nacional de Práticas Integrativas e Complementares no SUS PNPIC-SUS / Ministério da Saúde, Secretaria de Atenção à Saúde, Departamento de 
Atenção Básica. - Brasília : Ministério da Saúde, 2006.

33. Brasil. Ministério da Saúde. Secretaria de Ciência, Tecnologia e Insumos Estratégicos. Departamento de Ciência e Tecnologia. Política nacional de ciência, tecnologia e inovação em saúde / Ministério da Saúde, Secretaria de Ciência, Tecnologia e Insumos Estratégicos, Departamento de Ciência e Tecnologia - 2. ed. - Brasília : Editora do Ministério da Saúde, 2008. 44 p.

34. Brasil. Informe Técnicos Institucionais. Estratégia Nacional de Biotecnologia: interfaces com a saúde humana. Rev Saúde Pública. 2006; 40(5):938-40.

35. Perfeito, JPS. O registro sanitário de medicamentos fitoterápicos no Brasil: uma avaliação da situação atual e das razões de indeferimento. Dissertação (Mestrado em Ciências da Saúde) - Universidade de Brasília, Brasília, 2012.

36. Silveira PF, Bandeira MAM, Arraias PSD. Farmacovigilância e reações adversas às plantas medicinais e fitoterápicos: uma realidade. Revista Brasileira de Farmacognosia. 2008; 18(4):618-626.

37. Dias AA, Narvai PC, Rêgo DM. Tendências da produção científica em odontologia no Brasil. Rev Panam Salud Publica. 2008; 24(1):54-60.

38. Judice VMM, Baeta AMC. Modelo empresarial, gestão de inovação e investimentos de venture capital em empresas de biotecnologia no Brasil. Rev. adm. Contemp. 2005; 9(1):171-191.

39. Diretório de Grupos de Pesquisa no Brasil (DGPB). Conselho Nacional de Desenvolvimento Científico e Tecnológico (CNPq). Acessado em: 08/01/2013 Disponível em: http://dgp.cnpq.br/buscaoperacional/

40. Valarini N, Doi RK, Maciel SM, PoliFrederico RC. Biologia molecular na odontologia: métodos comumente utilizados na cariologia. Odontol. Clín.-Cient. 2011; 10(1):19-23.

41. Adjic $D$ et al. Genome sequence of Streptococcus mutans UA159, a cariogenic dental pathogen. Proc Nat Acad Sci. 2002; 99(22):14432-14439.
42. Vasconcellos KRF. et al. Avaliação in vitro da atividade antibacteriana de um cimento odontológico à base de óleo-resina de Copaifera multijuga Hayne. Revista de Farmacognosia. 2008; 18(Sup.0):733-738.

43. Barbosa RSS. Avaliação in vitro da atividade microbiana de extratos de fungos endofíticos frente a cepas presentes em infecções endodônticas. Dissertação de Mestrado (Mestrado em Patologia Tropical) Universidade Federal do Amazonas, Manaus, 2009.

44. Honório HM. et al. Aspectos clínicos da utilização do gel de papaína e cloramina na remoção de cárie dentária. RFO. 2009; 14(1):61-65.

45. Lopes PP. Análise da microinfiltração marginal em dentina hígida em restaurações de resina composta de um produto biotecnológico: gel de bromelina. Tese de Doutorado (Doutorado em Biotecnologia) Universidade Federal do Amazonas, Manaus, 2010 .

46. Campello RIC. et al. Uso do cimento Portland no reparo de fratura mandibular em ratos. Acta Cirurgica Brasileira. 2011; 26(6):16782674.

47. Soares AP. et al. Células-tronco em Odontologia. R Dental Press Ortodon Ortop Facial. 2007; 13(1):33-40.

48. Nakashima M. Bone morphogenetic proteins in dentin re- generation for potential use in endodontic therapy. Cytokine Growth Factor Rev. 2005; 16(3):369-376.

49. Nakashima M, Akamine, A. The application of tissue engineering to regeneration of pulp and dentin in Endodontics. J Endod. 2005; 31(10):711-718.

50. Laino G. et al. A new population of human adult dental pulp stem cells: a useful source of living autologous fibrous bone tissue (LAB). J Bone Miner Res. 2005; 20(8):1394-402.

51. Streckfus CF, Bigler LR. Saliva as a diagnostic fluid. Oral Diseases. 2002; 8(3):6976.

52. Teixeira EH. et al. Inhibition of oral streptococci binding to the acquired pellicle by algal lectins. Journal of Applied 
Revista Eletrônica Gestão \& Saúde ISSN: 1982-4785

Zilbovicius C, Ianni ÁMZ, Carnut L, TAJRA FS et al

Microbiology. 2007a; 103:1001-1006.

53. Teixeira EH. et al. Inibição da adesão bacteriana a película adquirida através de lectinas isoladas de algas marinhas das espécies Bryothamnion seaforthii e Bryothamnion triquetrum. In: XII Congresso Latino- Americano de Ciências do Mar - XII COLACMAR, 2007, Florianópolis. Livro de Resumos, 2007b.

54. Boeira Junior, B.R.; Echeverrigaray, S. Dentistry and molecular biology: a promising field for tooth agenesis management. Tohoku J Exp Med. 2012: 226(4):243-9.

Ianni AMZ. Desafios para um novo pacto
Biotecnologia e saúde pública: suas interfaces...

sanitário: biotecnologia e risco. Ciênc. saúde coletiva. 2011; 16(Sup.1):837-846.

\section{Participação dos autores}

CARNUT L atuou na concepção teórica, coleta de dados, análise e elaboração e redação final do texto;

TAJRA, FS atuou na concepção teórica, elaboração, análise e redação final do texto;

IANNI, ÁMZ atuou na concepção, análise crítica e redação final do texto;

ZILBOVICIUS, $\mathrm{C}$ atuou na concepção, análise crítica e redação final do texto.

Recebido: 30.01.2017

Revisado: 31.01.2017

Aprovado: 31.01 .2017 